\title{
AJENIDAD, DESARRAIGO Y NECESIDAD DE PERTENENCIA EN LA INVASIÓN DEL PUEBLO del espírttu de Juan Pablo Villalobos
}

\section{Foreignness, Uprooting, AND the NeEd to Belong in La inVASION Del PUEBLo Del espíritu, by Juan Pablo Villalobos}

Teresa García Díaz*

DOI: http://dx.doi.org/10.29043/liminar.v19i2.855

Resumen: El presente artículo introduce a Juan Pablo Villalobos como escritor innovador, que, entre otros temas, ha escrito sobre la inmigración desde diferentes registros y géneros. Se analizan los matices que emplea el autor a fin de mostrar que los personajes se enfrentan a múltiples dificultades para integrarse a un nuevo espacio y para establecer relaciones en la novela La invasión del pueblo del espíritu (2020). La soledad y la ajenidad atrapan a los personajes en ese nuevo espacio; y para analizar esta situación se acude a Marc Augé y su concepto de "no lugares". Asimismo, se reflexiona sobre la simbiosis que se crea entre el espacio y el tiempo, originada por la fugacidad y el movimiento en la trama de la novela; para dar cuenta de esto se recurre a Gaston Bachelard y Martin Heidegger. Por último, se estudia la singular voz narrativa múltiple que se une al lector para percibir, interpretar y narrar lo sucedido.

Palabras clave: Villalobos, Juan Pablo, narrativa, inmigrantes, simbiosis de tiempo y espacio.

Abstract: This paper introduces Juan Pablo Villalobos as an innovative writer that, among other topics, treats immigration from diverse perspectives and genres in his latter novels. Here we analyze the nuances with which the characters face numerous difficulties, in order to integrate themselves into a new space and establish relationships with other people in the novel La invasión del pueblo del espíritu [The Invasion of the Spirit's People] (2020). Solitude and otherness trap the characters in the new space; Marc Augé's concept of non-place is discussed here to analyze this situation. Likewise, we reflect on the symbiosis between space and time; this symbiosis comes from the fugacity and the movement within the novel's plot; in this respect, Gaston Bachelard and Martin Heidegger's insights are reviewed. Further, we study the peculiar multiple narrative voice, which joins together with the reader to perceive, interpret, and narrate events.

Key words: Villalobos, narrative, immigrants, time and space symbiosis.

\footnotetext{
* Teresa García Díaz. Doctora en Literatura Mexicana por la Universi dad Nacional Autónoma de México, México. Profesora-investigadora en el Instituto de Investigaciones Lingüístico-Literarias de la Universidad Veracruzana, México. Temas de especialización: narrativa latinoamericana y literatura comparada. Correo electrónico: teresagarciadiaz@yahoo.com. ORCID: 0000-0002-5291-1012.
}

Enviado a dictamen: 21 de septiembre de 2020 Aceptación: 23 de marzo de 2021 
El extranjero como un parásito nos envenena.

Maurice Barrès

El otro existe en lo contradictorio, quizá en lo paradójico, pues es invisible o hipervisible, pero casi nunca visible nada más.

Viet Thanh Nguyen

\section{Del Oriente y el Sur a "Barcelona"}

$\amalg$ lescritor mexicano Juan Pablo Villalobos nace en Lagos de Moreno, Jalisco, en 1973; en 2003 emigra a Barcelona, donde ha vivido desde entonces, con una estancia intermedia de tres años (entre 2011 y 2014) en Brasil. Mientras que sus primeras cuatro novelas - traducidas a muchas lenguas- suceden en México, las dos últimas suceden en Barcelona. Asimismo, en sus textos más recientes el escritor mexicano se ha interesado por incluir dentro de sus historias temáticas explícitamente relacionadas con la migración. Es el caso de Yo tuve un sueño. El viaje de los niños centroamericanos a Estados Unidos (2018a), un libro de crónicas híbridas emparentadas con la narrativa, que tratan la migración ilegal desde la perspectiva infantil. En ellas, el autor real y el autor implícito se transparentan para darles voz a cada uno de los niños o adolescentes protagonistas de las historias, quienes narran su periplo desde su lugar de origen hasta Norteamérica en busca de sus padres o algún familiar que los apoye en su huida desesperada para preservar su vida, debido a los niveles de violencia e inseguridad que se presentan en sus comunidades. Narra diferentes etapas de sus vidas, su infancia, toda la travesía en tierra de nadie, donde son totalmente vulnerables, así como su estancia en "las hieleras"l una vez que entran a Estados Unidos y los juicios para decidir si son aceptados o no como residentes de ese segundo país. La violencia, la soledad, el dolor, el hambre, el miedo, las vejaciones, incluso sexuales, oscurecen esas páginas.

Los códigos de la literatura para niños necesariamente son distintos de los de la literatura para adultos; sin embargo, la primera novela de Villalobos que puede considerarse como infantil, Un viaje cósmico a Puerto Ficción (2018b), tiene puntos de unión con el libro de crónicas de niños centroamericanos que se desplazan a
Estados Unidos. Esto puede apreciarse si, por ejemplo, se tiene en cuenta que en esta obra los protagonistas quedan desprotegidos porque sus padres se fueron al Norte, dejándolos en total ignorancia en cuanto a su ubicación. Ante la ausencia, por los problemas de salud de la abuela que los cuidaba, deciden emigrar en búsqueda de los padres, aunque harán una escala en "Puerto Ficción", locus donde sucede la trama, pues no tienen idea de dónde y cómo localizar a los progenitores, además de carecer de los medios para posibilitar un reencuentro improbable. ${ }^{2}$ Por otra parte, La invasión del pueblo del espíritu (2020) es una novela que se contextualiza en la migración y el asentamiento de orientales y sudamericanos en España, novela sobre la que reflexionaré en las páginas siguientes.

Por cultura general se sabe que desde sus orígenes el ser humano era nómada: largas caminatas de nuestros ancestros y las relaciones establecidas entre los distintos grupos dieron origen a quiénes somos y cómo somos en las distintas partes del mundo. ${ }^{3}$ La caminata está en el origen de la migración: nuestras facciones, nuestras tonalidades, nuestra dicción, nuestra manera de alimentarnos, costumbres y un sinfín de características del ser y el hacer que nos conforman como individuos tienen ese punto de inicio común. De la experiencia migrante puede afirmarse que del viaje y del aprendizaje vital compartido con personas de otros orígenes y costumbres el ser humano o el personaje muta y se transmuta en infinitas gradaciones.

Con el transcurrir temporal se crearon las fronteras, las naciones y la propiedad de los espacios, y entonces los viajeros de distintos orígenes, sobre todo los más pobres, se convirtieron en personas no gratas para los habitantes originarios y ya asentados en las diversas regiones. Costumbres, lenguajes, características físicas y comportamientos concomitantes agruparon a grandes sectores de población con sus singularidades, en contraste con otras geografías terrestres. Los nacionalismos y la sensación de pertenencia de los habitantes originales de un país (desde el siglo XVIII en Estados Unidos y desde el XIX en México, así como en diferentes años dependiendo de cada nación), propician que los inmigrantes sufran múltiples formas de menosprecio, 
juicios, rechazo, e incluso explotación, sometimiento y abuso. Dado que muchos individuos no saben aceptar ni entender lo diferente, las reacciones negativas al fenómeno de la inmigración "tienen que ver con el concepto del otro, de lo extraño, lo ajeno, lo que no me corresponde; con la nula preparación para aceptar cambios; con la dificultad y la imposibilidad de sentir empatía" (Langewiesche, 2018:13) Así, los diferentes tipos de orientales, los conosureños y los mexicanos nunca formarán parte integral de la comunidad barcelonesa en la novela La invasión del pueblo del espíritu, de esa ciudad tan internacional que resulta pueblerina: "la ciudad es grande pero el barrio es como un pueblo" (Villalobos, 2020:38).

En contraste, la otra perspectiva, la de los migrantes, tiene distintas implicaciones, como Aleksandar Hemon escribe: "La inmigración es una crisis ontológica porque nos obliga a negociar las condiciones de nuestra individualidad en circunstancias existenciales que cambian continuamente" (Hemon en Langewiesche, 2018:13). A medida que los migrantes se enfrentan a lo diferente y a lo desconocido, se ven obligados a ciertos cambios de comportamientos y hábitos para ser aceptados, pues tienen ciertas desventajas frente a los nativos del sitio al que llegaron. Por una parte, los inmigrantes pueden ser mano de obra barata, pero por otra son vulnerables debido a la indefensión que significa estar otra tierra sin permiso para estarlo o, si lo tienen, en muchas ocasiones no cuentan con asideros para aprehender una nueva forma de vida o para dominar una nueva lengua soslayando la propia. La idiosincrasia y las características físicas son también otros elementos que complejizan la integración en un nuevo espacio; por ello, a pesar de permanecer un largo tiempo en esa ciudad que les resulta extraña en su paisaje y en sus costumbres, muchos sujetos siguen siendo ajenos a ella.

Desde la perspectiva crítica, los antiinmigrantes tienen una mirada distinta del fenómeno y del individuo; se centran en la visión de cómo los afecta directamente su presencia, o qué beneficios o aportes le puede significar a la comunidad en que se encuentran: "El migrante se vende y se analiza en masa, sin personalidad, sin antes y después, como algo factual" (Langewiesche, 2018:12).
Por ejemplo, en la novela de Villalobos los orientales hacen funcionar las tiendas del barrio y esa es toda su participación en la vida comunitaria. Gastón surte de vegetales a clientes fijos, a restaurantes y al mejor futbolista del mundo; Max solía atender a los clientes en su restaurante; casi todos los personajes que emigraron tienen funciones de servicio para los habitantes del sitio en que eligieron vivir. El que llega, a no ser que tenga los medios económicos para salir adelante o más aún para invertir en el nuevo lugar en que busca asentarse y quizá integrarse al modus vivendi de los lugareños, será repudiado por algunos de los ciudadanos legales de ese país, pues ellos consideran que en menor o mayor medida va a quitarles o a poner en riesgo lo que poseen, o incluso a alejarlos de la posibilidad de poseerlo. El desarraigo tiene consecuencias para la vida cotidiana y emocional de los sujetos y trasciende sus vidas. ${ }^{4}$

\section{Lo inasible del tiempo y del espacio}

No escribimos sobre un lugar porque procedamos de él, sino para pertenecer aél. Andrés Neuman

Cada migrante y cada persona que es obligada a desplazarse contiene un relato complicado y distinto. Antonio Prete

Las características del espacio en que se desarrolla la novela La invasión del pueblo del espíritu acrecientan las posibilidades de proyectar ese lugar en distintas ciudades europeas. La nomenclatura para los orígenes de los habitantes del barrio, la inestabilidad de los dueños de los negocios y la problemática de la estratificación para definir los usos de los suelos de las diferentes zonas de la ciudad se suman para universalizar ese locus en que se desarrolla la trama que, aunque no es una réplica de la Barcelona que se conoce en la vida real, podría ser Barcelona u otra ciudad española cosmopolita. Esto se justifica en el hecho de que hasta cierto punto tiene un carácter neutro frente a tantas idiosincrasias que conviven ahí: tanto las de los originales, como las idiosincrasias propias de los habitantes de regiones 
cercanas, los extranjeros recién llegados o los habitantes añejos de ese espacio pero de otros orígenes que no han dejado de vivir de acuerdo con sus propias costumbres $y$ de sentirse extranjeros. ${ }^{5}$

Debe destacarse que los espacios abiertos y los espacios comunes son sumamente determinantes para la historia de La invasión del pueblo del espíritu. El traslado que han experimentado todos los personajes extranjeros, dejando atrás su vida y sus raíces para asentarse en la ciudad española, también implicó movimiento espacial. Viajaron para encontrar el sitio en que se construye un hogar donde sentirse seguros, plenos y en equilibrio, sin peligro de muerte ${ }^{6}$ o bien buscando solución a las problemáticas emocionales que les impiden una vida plena en el lugar de origen. Gastón se desprende de su vida conosureña, no tiene lazos sólidos con su tierra, al parecer fue un detonante de su viaje: "un sentimiento de inadecuación, de incompatibilidad; por la certeza de no pertenecer a la tierra donde se nació" (Villalobos, 2020:27). Se desconoce la forma de vida de Gastón antes de emigrar. Le era fundamental emigrar porque "poner distancia con la tierra natal era la condición de la libertad, su perorata del traslado territorial como un renacimiento, como una oportunidad de destruir la identidad pasada, de ser alguien nuevo o de no ser nunca nadie en particular" (Villalobos, 2020:27). Gastón no tiene lazos amorosos con sus familiares, por la manera en que se relata cómo intentan adueñarse de sus propiedades con malas artes. Solo le escriben mensajes telefónicos con esa finalidad. Para entender sus orígenes y traslados se debe partir del hecho de que Gastón "salió del mismo lugar que todos, del útero de una madre (que falleció cuando él era adolescente), de una tierra de la que se sintió expulsado porque siempre le resultó ajena, un error del destino que corrigió marchándose en cuanto le fue posible" (Villalobos, 2020:24). Su familia está compuesta por Max, Pol (hijo de Max, de quien Gastón es un segundo padre pues ayudó a criarlo) y sobre todo su mascota Gato; está muy asentado en ese lugar, trabajando en ese huerto que disfruta y le da paz, y ese círculo amistoso sustenta su estructura familiar en lo emocional.
Gastón vive caminando por la ciudad para tratar de resolver el conflicto de Max con la venta del espacio que contenía su restaurante; para conseguir una buena muerte para Gato, su perro, que es su familiar más cercano; para resolver la "locura" de Pol con sus certezas sobre los extraterrestres; para conseguir los permisos con el fin de que en una parte de su huerto funcione un restaurante para Max; para proveer con las papas conosureñas la alimentación del mejor futbolista del mundo (que, se sugiere, es Lionel Messi, y por lo tanto se sobreentiende que alude al equipo futbolístico al que pertenece y a la ciudad de Barcelona). Gastón convierte su día a día en caminatas continuas para posibilitar los encuentros, las conversaciones, y quizás la solución a tantas problemáticas de vida que le atañen. ${ }^{7}$ No se traslada fuera de la ciudad, pero vive moviéndose a través de la ciudad y del barrio: todo sucede en las plazas, el restaurante de Max, los diferentes negocios de los orientales, los parques, los bares, el huerto. Así, los desplazamientos de Gastón sostienen la trama de la novela. En ese contexto espacial, respecto a sus dos novelas ubicadas en Barcelona, dice Villalobos:

Lo que más me ha influido es el espacio público, que es muy diferente al de México o América Latina en general. Esas dos novelas, más allá de los personajes barceloneses, suceden en la calle, en las plazas, en los parques, playas, bares, restaurantes. [...] En mis novelas barcelonesas la trama se va enredando por el azar o la casualidad que solo puede producirse en el espacio público. Ahora pienso que narrar es como caminar, como pasear, deambular. Eso lo aprendí en Barcelona. (Villalobos en Gomila, 2020)

En la novela La invasión del pueblo del espíritu la trama se sostiene en los paseos de Gastón, con Gato y sin Gato - con la correa imaginaria del can recientemente fallecido-, por los sitios públicos donde se suscitan sus reflexiones y los diferentes encuentros con otros personajes. En estas circunstancias considero pertinente acudir a Marc Augé, para quien los lugares públicos o de tránsito son denominados "no lugares" por su transitoriedad y por ser comunes a todos y por lo 
tanto no pertenecer a nadie. Lugares públicos, lugares de todos: "Los no lugares son tanto las instalaciones necesarias para la circulación acelerada de personas y bienes (vías rápidas, empalmes de rutas, aeropuertos) como los medios de transporte mismos o los grandes centros comerciales, o también los campos de tránsito prolongado donde se estacionan los refugiados del planeta" (Augé, 1998:41). En la novela podrían sumarse a la lista de Augé los sitios por donde Gastón cruza o realiza sus peregrinajes. ${ }^{8}$ Los espacios son sitios de integración o de indiferencia, y por tanto de soledad y aislamiento cuando no se logra el sentido de comunidad y de preocupación por interrelacionarse o ayudar al otro. Al respecto, el filósofo abunda:

Las colectividades (o aquellos que las dirigen), como los individuos que se incorporan a ellas, tienen necesidad simultáneamente de pensar la identidad y la relación y, para hacerlo, de simbolizar los constituyentes de la identidad compartida (por el conjunto de un grupo), de la identidad particular (de tal grupo o de tal individuo con respecto a los otros) y de la identidad singular (del individuo o del grupo de individuos en tanto no son semejantes a ningún otro) (Augé, 1998:57).

Hay problemáticas de interrelación que se agudizan en los extranjeros pues nadie confía en nadie y todos sospechan de todos. Gastón tiene un grupo pequeñísimo con el que solía contar, integrado solo por su perro Gato, el mexicano Max y Pol, el hijo de Max. Tras la renuncia a la vida de Max, quien vegeta en el restaurante abandonado, tras la "locura" de Pol, que huye de la investigación que realiza en la Tundra por una paranoia $a^{9}$ que se convierte en una historia de vida extraterrestre, Gastón solo cuenta con los orientales con los que intenta interrelacionarse para solucionar los problemas de su "pequeña familia-grupo de acompañantes vitales" que posee en Barcelona, pues, como se mencionó antes, todos sus parientes argentinos por medio de artimañas solo quieren robarle sus propiedades en su tierra natal, obligándolo a malvenderlas para evitar que se las arrebaten.
En contraste con los espacios abiertos y comunes se da un proceso de invasión o apropiación como simple modus vivendi de los extranjeros que llegan y se asientan en esa ciudad y tienen un papel importante dentro de la trama. Cuando Gastón trata de negociar con un nororiental ${ }^{10}$ la recuperación del espacio del restaurante de Max, hay una serie de desconfianzas que los separan: "El nororiental de la frutería insiste en que Gastón se identifique apropiadamente si quiere hablar de negocios; necesita saber de dónde procede y a qué se dedica para poner a funcionar los códigos de confianza, o desconfianza, territorial y gremial" (Villalobos, 2020:17). Poco a poco irán acercándose y ganando confianza, aunque no solucionen el problema de Max..$^{11}$ Porque la necesidad de ser propietarios de un "espacio": casa, tienda, bar, restaurante, que es requerida para legalizar la vida de los orientales en la ciudad provoca que poco a poco el barrio cambie de propietarios: "los lejanorientales han ido comprándolo todo en el barrio. Los cafés, los bares, los restaurantes, comercios anticuados como mercerías o ultramarinos que transforman en bazares" (Villalobos, 2020:9).

La percepción del tiempo en la novela es muy particular, porque engloba la vida pasada en el país de origen de los personajes, su vida presente en la ciudad distinta y su vida futura que depende de muchos factores ajenos a su voluntad. Se le dice al lector que todo sucede "trece mil ochocientos millones de años después del nacimiento de nuestro Universo" (Villalobos, 2020:12). Esos acotamientos temporales le dan una relatividad muy singular. Recordemos que el narrador es finalmente el que establece esas coordenadas temporales y las usa para ubicar el origen de los personajes. También alude al asunto histórico: por ejemplo, la colonización de España y la relación entre la metrópolis y las "antiguas colonias", que es un tema constante en la novela y se relaciona con la cuestión migratoria. Y como se dijo, usa los puntos cardinales como orientaciones geográficas de manera constante. Lingüísticamente son usos únicos dentro de la novela, que establecen unidades de sentido propias y deícticas. 
Gastón vive en varios tiempos yuxtapuestos: las noticias de su familia argentina le llegan en pasado por las diferencias de horario, que provocan que los mensajes emitidos los lea como hechos pretéritos aunque hayan sido escritos en presente; asimismo, su futuro respecto a las decisiones que tomará con relación a las noticias que recibe es impredecible. Por ello, podría vincularse con la siguiente afirmación de Bachelard: "el tiempo es una realidad afianzada en el instante y suspendida entre dos nadas" (2002:11). La novela combate un tanto la nostalgia, porque los personajes viven su cotidianidad sin asirse a lo que eran en el pasado, o al menos las acotaciones de ese tipo son mínimas: escenas de la infancia de Pol, cuando Gastón lo recogía de la escuela, o escenas donde se refieren muy escuetamente las guerras de Oriente; en solo cinco líneas Yu describe muy fríamente las guerras y la muerte de la esposa.

En La invención del pueblo del espíritu todo está cambiando en ese presente que se proyecta hacia ese futuro cercano y se afianza en el pasado recién vivido de manera simultánea con el pasado remoto. ${ }^{12}$ A medida que hay cambio temporal, también se transforman la interioridad de los personajes, pues son seres mudables permanentes por vivir en un espacio extraño por ajeno. Parecieran vivir al día, porque están huyendo de algo, ocultan información a los otros, dudan de los demás y se sienten perseguidos: "la idea de lo discontinuo se impone sin la menor sombra de duda" (Bachelard, 2002:11), porque nadie está seguro de nada y todo está por cambiar.

Si como escribe Heidegger: "El ser-ahí, en tanto que este ser-en-el-mundo, es justamente un ser-con, un ser con otros" (2011:36), los personajes que están solos y no tienen certezas respecto a con quién cuentan están ambiguamente solos y acompañados de manera simultánea, como se lee en los dos epígrafes de la novela: "Estamos solos" de José Alfredo Jiménez y “No estamos solos" de Fox Mulder. Pues solo logran unirse para proteger la aparente vida extraterrestre que Pol llevará al huerto de Gastón para que sobreviva. Los personajes están solos en compañía y en su vida en común, y tristemente parecieran buscar como única alternativa la compañía de seres de otros planetas o de otras galaxias.

\section{Ese nosotros incorpóreo que siente, observa e interpreta}

Habitar un lugar es, en buena medida, planear una manera de marcharse.

Andrés Neuman

Somos todos iguales y vamos hacia los mismos fines.

Marguerite Yourcenar

Es muy particular la construcción de la voz narrativa, con matices que la enriquecen continuamente y la acercan al narratario casi desvaneciendo del todo la presencia tanto del autor implícito como del autor real, por ese logrado trabajo de casi convertir la voz en personaje y simultáneamente hacer que el lector sea parte de ese plural que narra la historia. El narrador está muy presente, estructura y organiza las páginas del discurso, apela de manera recurrente al lector, da explicaciones, menciona por qué no dice ciertas palabras y cómo se siente; su percepción ayuda a construir la historia. Constantemente hace guiños al lector para no dejarlo fuera de ninguna situación ni ocultarle ningún dato de los personajes:

nosotros siempre vamos a acompañar a Gastón, como si flotáramos detrás de él y pudiéramos acceder a sus sentimientos, a sus sensaciones, al flujo de su pensamiento. Somos unos entrometidos, en realidad, por lo que tendremos que ser cautelosos o podría echarnos de su lado y acabar con nuestro plan. Nuestro plan es llegar a la última página de este libro (que nadie imagine una conspiración), por eso tenemos que seguir a Gastón, en el presente hasta llegar al final (Villalobos, 2020:11).

La focalización de la voz se ubica en la espalda de Gastón, como si el narrador y el lector lo siguieran, porque él es el personaje que deambula estableciendo comunicación con todos los otros personajes, y entrando a los espacios cerrados cuando es necesario. Su cometido se logra cuando los lectores llegamos al final de la historia acompañados de ese narrador tan suigeneris. Asimismo, 
a nivel lingüístico el vocabulario suma a la fractura entre los seres humanos cuando refiere, por ejemplo, a: "el acento extraño con el que entona la lengua colonizadora" (Villalobos, 2020:10). Asimismo, cuando reiteradamente el narrador ubica a los personajes como pertenecientes a un grupo "proximoriental", "lejanorientales", "nororientales", "conosureño"; a especificaciones geográficas como "los límites del poniente del oeste, en la Península de una de las antiguas Colonias" (2020:25); al expresar de un personaje: "somos pueblos hermanos, nosotros nunca olvidamos las Colonias. Estamos juntos en eso" (2020:39); o al aludir al "campeonato continental” (2020:49) de fútbol. Se parodia el racismo y clasismo de los barceloneses con los extranjeros. Y va todavía más allá, cuando el narrador le recuerda al lector que cuando un extranjero habla: "Dice todo esto con otras palabras, usando la lengua colonizadora de una manera que trasluce otra estructura del pensamiento" (2020:33). No solo se trata de diferentes formas de expresión, sino de distintas maneras de percibir y entender el mundo, lo que explica más aún las fisuras existentes entre los personajes para interrelacionarse.

El narrador elude, selecciona y elige qué dice, qué no y cómo lo dice, y lo expresa tranquilamente: "Aquí no lo queremos nombrar, como tampoco nombramos otras cosas, algunas porque no tienen importancia, otras porque al negarnos a nombrarlas nos resultan todavía más ominosas" (Villalobos, 2020:35). Manifiesta una clara conciencia en las líneas de la novela, del proceso de recepción de lo no dicho, de lo ambiguo y lo subrayado, de esa manera se enfatiza una información que en apariencia no se quería dar. Paradójicamente al eludir, o silenciar, se privilegia y se omite enfatizando la atención dellector hacia ciertos puntos; como cuando el narrador se niega a nombrar la enfermedad de Gato: "Aquí no lo queremos nombrar, como tampoco nombramos otras cosas, algunas porque no tienen importancia, otras porque al negarnos a nombrarlas resultan todavía más ominosas" (Villalobos, 2020:35).

Incluso el narrador se burla tranquilamente del lector cuando dice: "no seamos charlatanes. Nadie puede entrar en la cabeza de un perro. Nosotros debemos conformarnos con Gastón, con esa responsabilidad tenemos más que suficiente. Se nos dio un poder para escribir esta historia. No abusemos de él" (Villalobos, 2020:36). Y le exige trabajo al lector en la recepción e interpretación de lo relatado: "la verdad no radica en la imagen, sino en el proceso de imaginar, en lo que sucede entre la mente y la materia, en cómo contamos esta historia" (2020:15). El lector debe completar lo eludido y entender el porqué del uso de ese recurso para el desarrollo de la historia. ${ }^{13}$ Con esa voz narrativa tan pensante, perceptiva y deseosa de parodiar, casi suma otro personaje o bien otra forma de interpretar lo narrado para el lector.

Ahora bien, las siguientes líneas que aparecen en la primera página de La invasión del pueblo del espíritu (2020) sobre el tiempo, el espacio, y la falta de límites entre ficción y realidad podrían pertenecer a muchas tramas, muchas novelas y muchas ciudades. Y ese es el terreno por el que el lector transita durante toda la obra:
El presente está aquí, mientras escribimos aquí y lee- mos aquí. Aquí. También el lugar, la ciudad en la que se desarrolla la historia, está aquí. En esta página, no hace falta buscarla más allá. Al fin y al cabo, el tiempo y el espacio son lo mismo. Nuestro lugar es el tiempo en el que transcurrimos; el presente es nuestro lugar de residencia. El pasado lo iremos entendiendo sobre la marcha, porque es la conexión entre el presente y el futuro. El pasado será el dedo que hará avanzar las páginas de este libro.
Demos la vuelta a la página porque el futuro está ahí (Villalobos, 2020:11).

Al aludir al espacio del papel dentro de la misma categoría que el espacio de los hechos, el narrador introduce al lector en el espacio de los acontecimientos; entonces, la función que contiene la ficción y la ruptura temporal y espacial se vinculan y se yuxtaponen para sustentar los deambulares de los personajes por las páginas, por sus propias vidas y por las de los sujetos que se suman a sus historias. Esas líneas, además de unir al autor implícito, al narrador y a los lectores por ese "nosotros" recurrente, aleja totalmente al autor real y ese es un gran logro de Villalobos, que hace lo mismo en su libro 
de crónicas pero con otros recursos estéticos, como se verá más adelante.

Los códigos de verosimilitud se ponen en entredicho por los recursos y matices de la voz narrativa y por la vida extraterrestre; sin embargo, Villalobos sale avante y logra ser creíble más allá de las peculiaridades en la forma de contar: "Me interesa cómo se puede hacer una literatura ensanchando las posibilidades de la verosimilitud. Esa es la pregunta que me planteo en cada libro" (Villalobos en Gaar, 2020:9).

En la novela todos huyen, todos tienen miedos y pareciera que: "La salvación podría existir. Pero nunca habrá un lugar donde salvarse” (Neuman, 2005:47). Todos se vigilan, se ocultan, conspiran, acosan, huyen, hacen planes, se organizan para sobrevivir y obtener los factores que suponen harán posibles sus anhelos. Para algunos el problema mayor es el que tienen dentro, es el problema del espíritu. Max desea regresar a su lugar de origen, aunque pareciera que es el fracaso con el restaurante el que lo orilla a repatriarse, pues como escribe Prete: "En realidad, no se tiene nostalgia de un lugar, sino de un tiempo vivido en ese lugar. No de la infancia, sino del tiempo que la infancia designa, a tiempo, que está definitivamente perdido. Ya no podremos volver a él" (Prete, 2010:122). Regresará a un sitio, pero ya no puede recuperar lo que tenía en él, aunque tampoco tiene cómo solucionar sus conflictos prácticos y vitales en Barcelona; por eso se va:

\section{Si en el orden espacial podemos movernos de un sitio a otro o volver de un punto de llegada al de partida, en el orden temporal no podemos hacer lo mismo. Esta disfunción es el fundamento de la imposibilidad del nostos y del dolor que dicha imposibilidad procura. En fin, puedo recuperar el lugar, pero nunca al mismo yo que vivió en aquel lugar (Prete, 2010:122-123).}

Llega un momento en que para el inmigrante, como escribe Neuman: "La patria del extranjero es la frontera" (2005:38), pues ya no pertenece ni al lugar de origen, ni al nuevo lugar. Ninguno de los personajes es igual a quien era cuando llegó a Barcelona: "Al mismo tiempo tenemos la ineludible realidad del yo transformado por la inmigración: al margen de qué personas hubiéramos sido, ahora estamos divididos entre nosotros-aqui [...] y nosotros -alli" (Langewiesche, 2018:13). Sin embargo, Gastón, para lograr que sus familiares conosureños no se queden con sus propiedades, decide vender todo con urgencia, aunque eso signifique quemar del todo sus naves en su patria. Es un personaje bondadoso y generoso, apoya económicamente al padre ladrón de Max para que pueda huir, ayuda también así con los gastos de viaje de Max. Gastón recuerda un tanto, como Villalobos menciona en una entrevista, al Cándido de Voltaire: "Su fisonomía descubría su alma. Le llamaban Cándido, tal vez porque en él se daban la rectitud de juicio junto a la espontaneidad de carácter" (Voltaire, 2013[1759]:4). Gastón tiene su vida resuelta, aunque está muy solo, y por ello puede ayudar a los otros. Acoge a Pol, surge un inicio de enamoramiento con la adormidera oriental, y un vínculo protector afectivo con la pequeña oriental Varya, que da bastante claridad al paisaje humano de la novela. Situación que remite al personaje de Voltaire: después de vivir todas las peores vicisitudes y sobrevivir a ellas con tremendas e irrecuperables pérdidas de todo tipo, Cándido tiene un espíritu y una bonhomía tan evidentes que, después de sortear tanta infelicidad y sufrimientos, su sirviente le dice:

Todo tiene relación en el mejor de los mundos posibles: porque si no os hubiesen expulsado del castillo por amor a la señorita Cunegunda, si no hubieseis sido entregado a la Inquisición, si no hubieseis atravesado América andando, si no hubieseis dado una gran estocada al barón y si no hubieseis perdido todos vuestros carneros de aquella buena tierra de Eldorado, no estaríais comiendo ahora mermelada de sidra y pistachos.

— Muy bien dicho — contestó Cándido-, pero lo importante es cultivar nuestra huerta (Voltaire, 2013[1759]:149).

Situación similar es la vivida por Gastón: debió dar dinero al abuelo de Pol para que huyeran tanto él como Max. Con la partida de su amigo, pierde la familia amistosa que lo sostenía y lo obligan a vender sus propiedades 
en valores mínimos, con lo cual se reduce su patrimonio considerablemente, debe cuidar de Pol, y sin embargo está optimista frente a lo que sí tiene y las virtualidades que se abren para un futuro cercano.

Como ha podido verse, la novela parece un constante cambio de tema o una "huida hacia delante" en términos airanos. Se trata de una estrategia narrativa que consiste en una forma de estructurar el texto, no desarrolla ni agota, cambia de tema, es digresiva. Por ejemplo, Aira en la novela Llanto escribe al respecto de este tema tan usado en su escritura:

[...] icómo representar, en el arte, el cambiar de idea? Porque se trata de algo muy común no sólo en el proceso de escribir algo más o menos extenso sino también en la vida cotidiana. En efecto, es lo más común del mundo que alguien empiece a hacer algo que se propone hacer, porque toda actividad tiene un comienzo, y en cierto punto cambia de idea, y su intención original se transforme o desvanezca (Aira, 1992:183).

Con esto quiero decir que en la novela que nos ocupa se yuxtaponen tramas y cambios de tema de manera constante por las múltiples líneas narrativas contenidas y apenas sugeridas. Son muchas las historias de vida que contiene la novela, aunque el hilo conductor narrativo sean los paseos de Gastón, y el elemento que une tantos microcosmos: el mundo de Max, el de los orientales, el de Gastón, el del ámbito inmobiliario y de terrenos en la ciudad, etcétera. De igual manera en la novela conviven muchos temas: la inmigración, la soledad, la ternura, los sujetos en el umbral de la vejez y la muerte, la paranoia, la orfandad, la pérdida, la desolación, los extraterrestres, etcétera. Se enfatiza que algunos personajes no son jóvenes ni inocentes, salvo los pequeños orientales. Y no se puede desdeñar que dos personajes están en los cincuenta y el abuelo de Pol en los setenta, lo que los coloca en el umbral de la vejez, y en la soledad que hay en torno a esas épocas desoladoras.

Por otra parte, la voz narrativa salta constantemente de tema, de manera parecida a como lo sugiere Aira en Cumpleaños: "las expectativas de cambio se construyen alrededor de un tema, pero el cambio siempre es un cambio de tema" (Aira, 1990:9). Ese mecanismo estructura la novela: nada es fijo, todo está en movimiento, cualquier cosa puede suceder, todo es imprevisible y cambiante en esa suma de historias que se suceden y trasponen, acompañadas por escenas o viñetas en los capítulos más breves. Aquí, al igual que en su libro de crónicas, Villalobos acude a grandes problemáticas sociales en historias personales, no en grande, al personalizar y a enfatizar en pequeñas situaciones temas enormes como el racismo y la xenofobia. El lenguaje tiene sentido dentro de la novela, hay un sutil intento de difuminar las identidades; por ejemplo, nunca se dice que Max es mexicano, pero se entiende por algunas características del personaje. Las indicaciones geográficas solo tienen sentido intratextualmente, fuera de las páginas no dicen nada. El lenguaje es una manera de nombrar las cosas; por ejemplo, no se habla de chiles como lo harían los mexicanos sino de pimientos; $y$ los calsots catalanes son cebollas alargadas en la novela. Es un uso muy lúdico del lenguaje donde se vacían los contenidos originales, los estereotipos, las identidades culturales, a través del lenguaje neutro para causar cierto extrañamiento en el lector, pero no el suficiente para crear un distanciamiento. Lo contrario de lo que hizo en No voy a pedirle a nadie que me crea (2016), la novela barcelonesa anterior, donde se apropia de todas las facetas del español, incluso del que habla un italiano.

El narrador hace crítica literaria y parece querer contener la novela para que no se desborden las historias, para que no enloquezcan ni se pierdan los personajes, para que haya verosimilitud y coherencia en el realismo que está presente en la novela. Algunas de sus reflexiones al respecto son del siguiente estilo: "si analizamos su comportamiento hasta ahora, como la subtrama de una novela que el narrador descarta por pereza o un mal hábito que se quiere hacer desaparecer a través de la negación" (Villalobos, 2020:101). O más adelante, cuando habla de "la consecuencia de atar cabos, de hilar la lógica del relato" (2020:190). Esos matices lo hacen un narrador muy sui generis, lo cual refresca mucho la lectura y resulta muy gozoso para el descubrimiento de sus particularidades sumamente innovadoras. 
Se acrecientan las capacidades narrativas de $\mathrm{Vi}$ llalobos al construir narradores tan distintos y tan distantes de él, con esa persistencia de la voz narrativa que se inmiscuye, opina, percibe, interpreta, espera y casi adquiere la categoría de personaje, pero tiene el vacío de identidad y carece de la capacidad de ser y vivir dentro del cosmos narrativo, más allá de narrar. La complicidad del narrador con el lector está más cerca del lector que del autor. Aunque ciertos datos se hermanan con el autor, como el locus de la historia, la base del inmigrante asentado por muchos años y algunas otras marcas autobiográficas. Solo nos queda imaginar ese futuro no narrado de Gastón y Pol, que quizá se guíen por el mapa en la cara de la adormidera, en los cruzamientos y peregrinajes que les quedan por hacer. Y tal vez ella acceda a mezclarse con un occidental, rompiendo las reglas de los orientales, pues, como escribe Neuman: "Todo es mestizo. El absoluto también" (Neuman, 2005:18).

Quizá los personajes logren asentarse del todo, al igual que las papas sureñas lograron crecer en esa tierra y las cebollas largas se lograron bajo un fuerte trabajo físico para irles dando la forma alargada, e incluso hacerlas crecer fuera de temporada. Un magnífico cierre de las historias es cuando de un lado del Algarrobo del huerto de Gastón descansa Gato y al otro lado las bacterias alienígenas que recién fueron sembradas en un estanque. Vale la pena insistir en que, como dice Cándido: "todo está muy bien, pero cultivemos nuestro jardín” (Voltaire, 2013[1759]:164). Podemos ignorar lo esencial de los sujetos y de sus vidas, como expresa la voz narrativa, hasta un olor como el de Gastón puede distraernos: "como nos ha distraído a nosotros" (Villalobos, 2020:68). Podemos perdernos en la vida y en la literatura, aunque siempre la muerte y la nueva vida yacerán en un mismo espacio y tiempo, en ese instante que es el ahora y es el momento de invasión del pueblo del espíritu. Frase que alude tanto a esa posible vida extraterrestre que iniciará su estar en la tierra, como al optimismo de Gastón por recuperar la salud mental de Pol y sembrar su huerto acompañado por la adormidera e iluminado por la inocencia de Varushka. Haciendo énfasis en el diminutivo de su nombre, que es Varya, para enfatizar su claridad y esperanza en su vida futura y la de todos los emigrantes que se tornan en dueños de la ciudad que habitan solo por vivir allí, convirtiéndose en parte de La invasión del pueblo del espíritu.

\section{Notas}

${ }^{1}$ A los lugares donde - enjaularon - a los niños migrantes en condiciones de hacinamiento y sin los requerimientos mínimos que necesita una persona, y más aún un niño, para sobrevivir en buenas condiciones físicas y emocionales, les llamaban - hieleras - porque las temperaturas eran en extremo frías, aumentándolo que aumentaba el sufrimiento y la salud de esos pequeños.

${ }^{2}$ Los niños están solos y tienen miedo. En un momento crítico de la trama, Sabina, la niña personaje narradora, reflexiona:

Estábamos más solos que nunca en la vida. No teníamos un hogar, ni una familia, ni una casa.

¿Dónde estarían papá y mamá?

¿Por qué no venían a rescatarnos?

¿Por qué no habían vuelto del norte, si hasta los animales migratorios regresaban cada año?

Éramos rémoras sin casa, sin nadie a quien adherirnos para que nos alimentara y protegiera.

Estábamos a la deriva, como si el oleaje del mar nos arrastrara y no supiéramos nadar y nuestros pies no alcanzaran a tocar la arena (Villalobos, 2018b:126-127).

${ }^{3}$ Asimismo, el lugar de nacimiento marca una gran parte de nuestra esencia. El origen determina quién se es: “Nacer es nacer en un lugar, tener destinado un sitio de residencia. En este sentido el lugar de nacimiento es constitutivo de la identidad individual, y ocurre en África que al niño nacido fuera del pueblo se le asigna un nombre particular relacionado con un elemento del paisaje que lo vio nacer. El lugar de nacimiento obedece a la ley de lo 'propio' y del nombre propio [...]" (Augé, 1998:59).

${ }^{4}$ Como lo expresa Villalobos, esta problemática es muy visible en los últimos tiempos: "el problema es que las comunidades cada vez se han vuelto más hostiles, se han ido desintegrando, se han ido convirtiendo en la suma de muchas individualidades. La pérdida del sentido de comunidad tiene que ver con el modelo eco- 
nómico, con el capitalismo, y más en particular con el neoliberalismo, que ha instaurado la ley de la selva, la competitividad del más fuerte, del más apto, esa falacia de la meritocracia. La degradación del espacio público es el mejor ejemplo: el espacio público se ha convertido en un lugar de intercambios comerciales, ha ido perdiendo su noción de ágora, de lugar de encuentro" (Maristáin, 2020).

${ }^{5} \mathrm{Al}$ referirse a los habitantes extranjeros en Barcelona, en una entrevista Villalobos expresa que: "Eso sucede mucho entre los extranjeros, asumir la ciudad como un lugar donde estás físicamente pero no sentimentalmente. Quizá la ciudad, o más bien, la sociedad barcelonesa, lo fomenta, porque no es fácil apropiarse de Barcelona, hay que esforzarse, hay que insistir, ser terco. Conozco a varios colegas que pasaron por aquí en tiempos recientes sin echar raíces ni tener ganas de hacerlo" (Villalobos en Gomila, 2020).

${ }^{6}$ Niko, el nororiental de la frutería, "[1] explica que en su tierra natal no hay trabajo ni tierra para trabajar, que la tierra fue devastada en la última guerra de fronteras entre los nororientales del norte del norte, y los nororientales del sur donde murió su esposa, la madre de su hija" (Villalobos, 2020:19).

${ }^{7}$ Para Heidegger el movimiento está directamente relacionado con el tiempo, y quizá por ello se puede aventurar que la relatividad, lo instantáneo y lo impredecible del devenir de Gastón y de la trama crean un vínculo que detiene y acelera el tiempo de manera arbitraria: "Puesto que el tiempo no es un movimiento, tendrá que ser algo relacionado con el movimiento" (Heidegger, 2011:29). Además, porque, como el filósofo alemán expresa, "[c]ada punto, como un ahora, es el posible antes de un después; y como después, es el después de un antes" (2011:31), así que, por decirlo de alguna manera, los ahora, los antes y los después de mezclan y se integran en ese movimiento permanente que es el ahora de Gastón y todos los demás personajes. Sobre todo porque "[c]ualquier anterioridad y posterioridad puede determinarse a partir de un ahora, que en sí mismo es arbitrario" (2011:31), y más aún cuando ese ahora concluye preservando la vida extraterrestre según las creencias de Pol y de todos sus seguidores. Y porque pareciera que el futuro está en el papel: "Demos la vuelta a la página: el futuro está ahí” (Villalobos, 2020:4).

${ }^{8} Y$ ese no lugar al que refiere Augé: "en el momento mismo en que la unidad del espacio terrestre se vuelve pensable y en el que se refuerzan las grandes redes multinacionales, se amplifica el clamor de los particularismos: de aquellos que quieren quedarse solos en su casa o de aquellos que quieren volver a tener patria, como si el conservadurismo de unos y el mesianismo de los otros estuviesen condenados a hablar el mismo lenguaje: el de la tierra y el de las raíces" (Augé, 1998:41).

${ }^{9}$ El narrador acota respecto a la ansiedad de Pol que "las condiciones inhumanas de la Tundra lo han roto, produciendo una sobredosis de hormonas del estrés, y la manera en que esta enajenación se manifiesta es una crisis de paranoia" (Villalobos, 2020:96). Aunque el tema de los extraterrestres ya había aparecido en otros textos de Villalobos, aquí se subraya hasta con la perspectiva de Gastón que: "la ilusión es igual de engañosa que la paranoia, ambas crecen sin parar, perfectas, invencibles, hasta que se topan con la realidad, la inapelable realidad" (2020:102).

${ }^{10}$ El uso de referencias en relación con los puntos cardinales como las de los orientales, "nororiental", "lejanoriental", etcétera; y las distintas combinaciones que Villalobos realiza para ubicar los espacios geográficos son términos propios de la novela. Lingüísticamente se suman a la neutralidad del lenguaje del que hablaré más adelante, cuando me refiera al narrador.

"l "No puedo vender. El restaurante es para mi hermano, viene a vivir aquí con su familia y necesitamos la propiedad del local para tramitar el visado" (Villalobos, 2020:12).

${ }^{12}$ Situación que puede avecinarse al sentido de la siguiente reflexión filosófica de Bachelard: "el tiempo podrá renacer, pero antes tendrá que morir. No podrá transportar su ser de uno a otro instante para hacer de él una duración" (2002:11).

${ }^{13}$ Hace crítica literaria a la hora de narrar, parodiando y haciendo reír o, por lo menos, sonreír al lector: "Estamos cansados de historias de resentidos, estamos hartos de enaltecer el rencor y las frustraciones" (Villalobos, 2020:15). 


\section{Referencias}

Aira, César (1990). Cumpleaños. Buenos Aires: Mondadori. Aira, César (1992). Llanto. Rosario: Beatriz Viterbo.

Augé, Marc (1998). Los “no lugares”. Espacios del anonimato. Barcelona: Gedisa.

Bachelard, Gastón (2002). La intuición del instante. México: Fondo de Cultura Económica.

Gaar, José Antonio (2020). "Juan Pablo Villalobos y su vocación por la brevedad". En Nexos, 13 de octubre. Disponible en https://cultura.nexos.com. $\mathrm{mx} /$ ?author_name=jose-antonio-gaar\&fbclid=IwAROIqhDEkp5wpGPLRmFPwfCKBI7W-1SPHivOz_Yq5aYtBZ6BgnIjVxJyrOg (consultado el 03 de julio de 2020).

Gomila, Andreu (2020). "Juan Pablo Villalobos: 'Narrar es como caminar, como pasear, deambular. Eso lo aprendí en Barcelona"'. En Festival de Barcelona [blog], 13 de abril. Disponible en https:/www.barcelona.cat/ grec/es/blog/juan-pablo-villalobos-narrar-es-comocaminar-como-pasear-deambular-eso-lo-aprendi-enbarcelona (consultado el 13 de abril de 2020).

Heidegger, Martin (2011). El concepto de tiempo. Madrid: Trotta.

Langewiesche, William (2018). "En tierra de nadie". En Rolando Arrieta, Pilar Cebrián, Aleksandar Hemon,
Eva Hoffman, Jamaica Kincaid et al., En tierra de nadie. Querétaro: Gris Tormenta, pp. 33-39.

Maristáin, Mónica (2020). "Juan Pablo Villalobos: 'Estamos condenados a la soledad, es muy difícil que el amor prevalezca en sociedades competitivas y egoístas"'. En Infobae, 20 de abril. Disponible en: https://www. infobae.com/cultura/2020/04/20/juan-pablo-villalobos-estamos-condenados-a-la-soledad-es-muy-dificilque-el-amor-prevalezcan-en-sociedades- (consultado el 22 de mayo de 2020).

Neuman, Andrés (2005). El equilibrista. Barcelona: Acantilado.

Prete, Antonio (2010). Tratado de la lejanía. Valencia: PreTextos.

Villalobos, Juan Pablo (2016). No voy a pedirle a nadie que me crea. Barcelona: Anagrama.

Villalobos, Juan Pablo (2018a). Yo tuve un sueño. El viaje de los niños centroamericanos a Estados Unidos. Barcelona: Anagrama.

Villalobos, Juan Pablo (2018b). Un viaje cósmico a Puerto Ficción. México: Fondo de Cultura Económica.

Villalobos, Juan Pablo (2020). La invasión del pueblo del espíritu. Barcelona: Anagrama.

Voltaire, François-Marie Arouet (2013[1759]). Cándido o el optimismo. Madrid: Edaf. 